\title{
Sobre el ámbito de aplicación del procedimiento concursal de reorganización \\ (Corte de Apelaciones de Santiago)*
}

\author{
Comentario de Jaime Alcalde Silva**
}

Santiago, once de enero de dos mil dieciocho.

\section{VISTOS Y TENIENDO PRESENTE:}

Primero: Que el abogado don Rodrigo Zegers Reyes, actuando en representación de Cooperativa de Ahorro y Crédito para el Desarrollo FINANCOOP, dedujo un recurso de queja en contra de la señora Juez suplente del Trigésimo Juzgado Civil de Santiago, doña Claudia Salgado Rubilar, por las faltas o abusos que ésta habría cometido al dictar la resolución del 27 de septiembre de 2017, que rechazó la reposición que su parte dedujo en contra de la resolución que denegó la solicitud de reorganización judicial que había promovido la Cooperativa.

Explica que el 24 de agosto del año en curso [2017] su parte ingresó ante ese Tribunal una petición de reorganización, al amparo de las disposiciones contempladas en los artículos 54 y siguientes de la Ley número 20.720, sobre reorganización y liquidación de empresas y personas. Al efecto, y luego de dar ejecución a diligencias previas a proveer derechamente su solicitud, con fecha 11 de septiembre de 2017 se denegó lo pedido por la recurrente, en resolución que transcribe en su integridad. FINANCOOP dedujo entonces reposición con nuevos antecedentes materiales, pese a lo cual la señora juez rechazó ese recurso, aduciendo que no se aportaron antecedentes distintos de los analizados en la solicitud que se pretendía enmendar.

Como primera falta o abuso grave denuncia que su parte dio complimiento a todos los requisitos previstos por el artículo 57 de la Ley 20.720, pese a lo cual se desestimó su requerimiento sin mediar causa legal alguna, sino fundándose en una exigencia que la ley no contempla, como es el supuesto deber de acreditar insolvencia, requisito que emanaría del espíritu de la ley concursal. Manifiesta que una vez reunidos los requisitos que la ley estatuye, es deber del tribunal acceder a lo solicitado, lo que se desprende de

* El autor agradece los comentarios hechos por el Profesor Juan Luis Goldenberg durante la preparación de este comentario.

** Licenciado en Ciencias Jurídicas, Pontificia Universidad Católica de Chile. Doctor en Derecho, Universidad de Valencia. Profesor de Derecho Privado, Pontificia Universidad Católica de Chile. Correo electrónico: jcalcald@uc.cl. 
los términos de que se vale el legislador al establecer, con voz imperativa, en el artículo 57 inciso primero de ese cuerpo legal, que el tribunal competente "dictará" la resolución correspondiente.

Enfatiza los términos y conclusiones del informe en derecho aparejado por el profesor don Juan Esteban Puga Vial, y [de la] jurisprudencia emanada de tribunales superiores de justicia, para concluir que es forzoso a un tribunal dictar la resolución de reorganización a que se refiere el artículo 57 de la Ley $\mathrm{N}^{\circ} 20.720$, porque la ley se satisface con ellos.

Insiste en que la acreditación de insolvencia no es requisito para acogerse a una reorganización contractual [sic], de manera que no es necesario acreditar que el peticionario se encuentra en aquel estado de iliquidez crónica e irremontable, asimilada por la señora Juez recurrida a la insolvencia.

En segundo lugar, expresa que hay falta o abuso grave al negar crédito la sentenciadora a [los] antecedentes entregados por FINANCOOP que en todo caso acreditan su estado de insolvencia, a lo menos potencial. Se refiere a datos materiales que dan cuenta que entre el 16 de agosto y el 15 de septiembre de 2017 surgieron 1.619 depósitos a plazo por la suma de $\$ 14.774 .245 .885$ que no pudieron ser pagados ni renovados. Así, un certificado extendido por el gerente de operaciones de la Cooperativa y [el] soporte magnético contenido en un disco compacto detallan todos y cada uno de los más de mil depósitos a plazo que no pudieron ser pagados ni renovados en esa época, no obstante lo cual la sentenciadora les desconoció toda importancia, declarando sin lugar la reposición promovida. Califica dicha decisión como arbitraria y caprichosa, toda vez que su parte se ha esmerado en cumplir el estándar pedido por la recurrida, superior al exigido por la ley, y de igual modo se niega lugar a lo que pide.

Rechazar la solicitud y la posterior reposición constituye, en su parecer, una falta o abuso grave cometida en el contexto de un procedimiento judicial voluntario en el que sólo cabía acceder a lo pedido por su parte.

SEgundo: Que, informando al tenor del recurso, doña Claudia Pamela Salgado Rubilar, secretaria titular del $30^{\circ}$ Juzgado Civil de Santiago, describe a grandes rasgos los fundamentos del recurso deducido en su contra, y aduce que dado que la que se pretende atacar por esta vía disciplinaria se pronuncia sobre una resolución que a su vez fue objeto de un recurso de reposición deducido en tiempo y forma, el deducido aquí ha perdido oportunidad y carece de fundamento, lo que conduce a sostener que no hay abuso de su parte. Argumenta que concedió un recurso de apelación conforme a las reglas generales, pero que esta Iltma. Corte lo declaró posteriormente inadmisible, lo que también lleva a sostener que no hay falta o abuso posible de corregir por esta vía.

Esgrime, sin perjuicio de lo que viene argumentando, que las razones de fondo que tuvo presentes para desechar la solicitud de la recurrente son las que se expresan en la resolución de 11 de septiembre de 2017 y, posteriormente, en la de 27 del mismo mes y año, que decidió la reposición. Explica que la peticionaria misma es quien argumenta que FINANCOOP funcionó con normalidad durante once años, siendo del todo viable y cumpliendo con cadenas de pagos hasta el 15 de agosto del año en curso, cuando fue 
notificada de la resolución dictada por el $23^{\circ}$ juzgado Civil de Santiago en la causa rol C-20.456-2017, caratulada "Fisco de Chile con Cooperativa para el Desarrollo FINANCOOP”, a consecuencia de la cual entraron en vigencia diversas medidas que provocaron su paralización, dañando su liquidez, por lo que necesitaba convenir con los acreedores un plan que le permitiera seguir adelante con las operaciones propias de su giro y, en definitiva, salvaguardar de mejor modo los intereses de sus socios, ahorrantes y trabajadores. Tuvo presente ese planteamiento, los antecedentes que dan cuenta de la historia fidedigna del establecimiento de la Ley número 20.720 y las reflexiones efectuadas por el profesor Puga Vial en una obra de 2015 [sic] para rechazar la petición que se sometió a su conocimiento.

Agrega que los nuevos antecedentes aportados en la reposición, entre los cuales se encuentra un informe en derecho suscrito por el profesor Puga, en nada alteran lo que originalmente decidió, razón que tuvo en cuenta para desestimar ese arbitrio. Concluye aseverando que más allá de las concepciones doctrinales y apreciaciones subjetivas que puedan sostener las partes, lo cierto es que el tribunal requiere de antecedentes que califiquen como objetivos, esto es, carentes de cualquier elemento incierto, confuso y ajeno al pensar o sentir, para estimar que la insolvencia, y no otras razones, es lo que lleva a impetrar el procedimiento. En consecuencia, estima que no cometió faltas o abusos ni en la resolución originalmente dictada ni en la que desestimó el recurso de reposición, sino que actuó según fundamentos suficientes y dentro de las facultades que la ley entrega a todo juez o tribunal.

Tercero: Que el Mensaje Presidencial que dio origen a la tramitación del proyecto que se transformó en la actual Ley 20.720, sobre reorganización y liquidación de empresas y personas, da cuenta del propósito general que tuvo en cuenta por el legislador para dictar reglas en materia concursal, cuyo [sic] lleva a identificar como idea matriz del proyecto de ley la de "establecer un nuevo régimen general de los procedimientos concursales destinados a reorganizar o liquidar los pasivos y activos de una empresa deudora, y a repactar los pasivos o liquidar los activos de una persona deudora...”. El orden seguido por el legislador, plasmado explícitamente en la preceptiva que hoy se encuentra vigente, es el de considerar la reorganización concursal a la par de otros procedimientos, sin que por ello comparta con estos últimos la misma naturaleza jurídica ni exija la previa concurrencia de requisitos comunes.

Cuarto: Que el capítulo III de la Ley número 20.720 contiene las normas sobre el procedimiento concursal de reorganización judicial, la que es caracterizada por las exigencias que el artículo 56 de la mencionada ley impone al peticionario en este caso. La protección de los intereses de acreedores y deudores y el correcto funcionamiento de la cadena de pagos en el mercado, unido a los propósitos perseguidos por el legislador que se han reseñado en el motivo precedente, permiten concluir que no hay más requisitos para el solicitante que aquellos expresa y determinadamente prescribe la norma que se ha citado, entre los cuales no se encuentra la insolvencia, actual o potencial, del deudor. En efecto, de lo que se trata es que la empresa pueda reestructurar sus pasivos, 
de manera de posibilitar el pago de las acreencias y evitar de ese modo un estado de insolvencia que le lleve a la liquidación.

Quinto: Que, en efecto, la finalidad del legislador fue concebir soluciones concursales que no se fundamentaran exclusivamente en el fenómeno de la insolvencia. Así, mientras el procedimiento de liquidación de la empresa o persona deudora persigue favorecer el cobro de los acreedores, en la reorganización es el deudor quien busca reordenar sus pasivos por vía judicial, con independencia de si las acreencias que existen en su contra se encuentran pendientes de exigibilidad o vencidas.

Sexto: Que la diferencia entre uno y otro procedimiento es más relevante aun si se tiene en cuenta que, conforme a los antecedentes proporcionados por el recurrente, no rebatidos en el informe ni en estrados, antes de formularse la petición que se examina, ya existían numerosos depósitos a plazo por un monto total de $\$ 14.774 .245 .885$ que no pudieron ser pagados ni renovados, lo que desde luego incide en la cadena de pagos y la capacidad operativa de FINANCOOP.

SÉPTIMO: Que el recurso de queja tiene por finalidad dejar sin efecto resoluciones judiciales y reprimir faltas o abusos graves cometidos por la magistratura, en la medida que éstos conduzcan al pronunciamiento de una decisión contraria a derecho.

OCTAvo: Que la falta y abuso son consustanciales al recurso de queja, del mismo modo que la infracción de ley lo es respecto del recurso de casación en la forma y en el fondo; y el agravio respecto del recurso de apelación. Constituye falta o abuso desconocer las consecuencias previsibles de la negativa a decretar la reorganización, pese a reunirse todos los requisitos que la ley impone para pronunciarla, imponiendo a su vez condiciones, como la insolvencia, que este procedimiento no considera. Al actuar de este modo, la señora juez recurrida cometió falta o abuso que debe remediarse por esta vía extraordinaria.

Por las razones expresadas, y de acuerdo con lo dispuesto por los artículos 545, 548 y demás pertinentes del Código Orgánico de Tribunales, se acoge el recurso de queja deducido por el abogado don Rodrigo Zegers Reyes en contra de la señora juez suplente del Trigésimo Juzgado Civil de Santiago doña Claudia Salgado Rubilar, y[,] en consecuencia[,] se dejan sin efecto las resoluciones de 11 y 27 de septiembre de 2017 y[,] en cambio[,] se decide que se hace lugar a la apertura del proceso de reorganización de la Cooperativa de Ahorro y Crédito para el Desarrollo, FINANCOOP, en los términos que pasan a especificarse enseguida, en resolución separada.

No se dispone la remisión de estos antecedentes al Tribunal Pleno, atendida la naturaleza y entidad de la inobservancia constatada.

Redactó el abogado integrante señor Mery.

Regístrese y comuníquese.

Rol 11.465-2017. 
Pronunciada por la Séptima Sala de la Iltma. Corte de Apelaciones de Santiago, presidida por el Ministro señor Omar Astudillo Contreras e integrada por la Ministro señora Adelita Ravanales Arriagada y por el Abogado Integrante señor Héctor Mery Romero. No firma la Ministro señora Ravanales por encontrarse ausente. Autoriza el (la) ministro de fe de esta Iltma. Corte de Apelaciones de Santiago.

\section{COMENTARIO}

La Ley 20.720 (LRLAEP) se limita a señalar que el objeto de un procedimiento concursal de reorganización es la reestructuración de los pasivos y activos de una empresa deudora (artículos $1^{\circ}, 2^{\circ}$ núm. 1 y 60) y que a él solo pueden someterse esta clase calificada de deudores (artículos $2^{\circ}$ núm. 29 y 54) ${ }^{1}$. Entonces, y para lo que aquí interesa, son susceptibles de quedar incursas en una reorganización todas las personas jurídicas privadas, con o sin fines de lucro (artículo $2^{\circ}$ núm. 13 LRLAEP), siendo el único límite la subsistencia de la ficción de su personalidad jurídica (artículo 545 CC). Tratándose de una cooperativa, como sucede con FINANCOOP, ella subsiste después de disuelta hasta que se complete su liquidación (artículo 48 LGC). Leída literalmente, la normativa concursal pareciera dar a entender que cualquier persona jurídica puede someterse a un procedimiento de reorganización tanto en cuanto subsista su personalidad jurídica, sin importar que ella ya no sea viable de continuar actual o potencialmente con su giro, como ocurre cuando se trata de una cooperativa en vías de disolución. Sin embargo, el sentido de las reglas aplicables muestra que en la situación que ahora se comenta se está ante un caso de interpretación restrictiva, lo que significa que, en realidad, el mentado procedimiento concursal se debe aplicar a menos situaciones que aquellas que su tenor literal parece comprender (artículo 23 CC).

El fallo recién reproducido resuelve esta cuestión de manera oblicua, pues la causa sobre la que incide (aquella tramitada bajo el rol núm. 22.908-2017 ante el 30 Juzgado Civil de Santiago) estaba relacionada con otra (aquella seguida ante el $23^{\circ} \mathrm{Juzgado}$ Civil de Santiago bajo el rol núm. 20.456-2017) donde se discutía la disolución de la cooperativa que solicitaba paralelamente su propia reorganización. Por eso, una breve contextualización resulta indispensable. El 15 de septiembre de 2017, el Consejo de Defensa del Estado y el Departamento de Cooperativas del Ministerio de Economía presentaron una demanda de disolución forzada de la Cooperativa de Ahorro y Crédito para el Desarrollo FINANCOOP Limitada conforme con las reglas del juicio sumario (acción de la que trata el artículo 43 LGC), habiendo comenzado esos autos por una solicitud de diversas medidas precautorias (retención de bienes, prohibición de celebrar actos y contratos, suspensión de ciertos actos de la cooperativa y nombramiento de un interventor). A su vez, el 24 de agosto de 2017, vale decir, un par de semanas antes, pero

${ }^{1}$ Cuestión aparte son los problemas que presenta la definición de empresa deudora del artículo $2^{\circ}$ núm. 13 LRLAEP, pese a que la doctrina nacional no se ha ocupado mayormente de las dificultades que de ahí surgen. 
después de solicitadas las medidas precautorias enderezadas a asegurar el resultado de la acción destinada a disolver la cooperativa, y cuando ya su situación era conocida por la prensa, FINANCOOP había presentado su solicitud de reorganización ante otro tribunal.

Ambos procedimientos comenzaron a tramitarse en forma paralela, hasta que por sentencia de 11 de septiembre de 2017 fue rechazada la solicitud de reorganización por parte del $30^{\circ}$ Juzgado Civil de Santiago, el que estimó que no estaba acreditado el estado actual de insolvencia o de cesación inminente de pagos por parte de la cooperativa (considerando $6^{\circ}$ ), el que constituiría el presupuesto objetivo para dar curso a dicho procedimiento concursal (considerando $5^{\circ}$ ). Debido a que el sistema de recursos en el marco de los procedimientos concursales es estricto (artículo $4^{\circ}$ LRLAEP), FINANCOOOP intentó revertir esta decisión mediante una reposición con apelación subsidiaria, siendo rechazado el primero de esos recursos por el propio tribunal, mientras que el segundo fue declarado inadmisible en alzada. Alegando una falta o abuso en la dictación de la resolución que rechazó la reposición por no haber tenido en cuenta los nuevos antecedentes aportados (artículo 181 CPC), la cooperativa interpuso un recurso de queja ante la Corte de Apelaciones de Santiago (artículo 545 COT). Fue conociendo de ese recurso que dicha Corte dictó la sentencia que ahora se comenta, donde dejó establecido que debía darse curso al procedimiento de reorganización de FINANCOOP porque ya existían numerosos depósitos a plazo que no pudieron ser pagados ni renovados, lo que incidía en la cadena de pagos y la capacidad operativa de la cooperativa (considerando $6^{\circ}$ ). Acto seguido y de manera separada, la Corte de Apelaciones de Santiago dictó la correspondiente resolución de reorganización (artículo 57 LRLAEP).

El argumento de la Corte para acoger el recurso de queja fue que las distintas soluciones concursales que articula la LRALEP no se fundamentan exclusivamente en el fenómeno de la insolvencia, porque la reorganización se endereza a reordenar el pasivo por vía judicial y no a favorecer el cobro de los acreedores con la realización de los bienes del deudor (considerandos $4^{\circ}$ y $\left.5^{\circ}\right)^{2}$. Esto es cierto. Sin embargo, detrás había existido una negociación entre la cooperativa y el Estado para conducir la solución del problema por la vía concursal y no societaria, vale decir, para favorecer la reorganización y no la disolución forzada. Esto suponía llegar a una transacción (finalmente materializada mediante el avenimiento que fue presentado al tribunal el 4 de enero de 2018), merced a ello, el Consejo de Defensa del Estado y el Departamento de Cooperativas se desistían de la acción de disolución seguida ante el $23^{\circ}$ Juzgado Civil de Santiago, permitiendo así que continuase el procedimiento concursal.

El criterio señalado por la Corte obliga a indagar acerca del verdadero sentido de los procedimientos de reorganización. Pues bien, el término «reestructuración» de la LRLAEP (artículos $2^{\circ}$ núm. 1 y 60) toma como base lo dispuesto en el artículo $1^{\circ}$ de la ley concursal colombiana (Ley 1.116, de 2006, sobre insolvencia empresarial), según este, «[e]l proceso de reorganización pretende a través de un acuerdo, preservar

${ }^{2}$ Esa era la definición del juicio de quiebras que daba el artículo $1^{\circ}$ II del Libro IV del Código de Comercio. 
empresas viables y normalizar sus relaciones comerciales y crediticias, mediante su reestructuración operacional, administrativa, de activos o pasivos» ${ }^{3}$. A su vez, esta ley tenía como antecedente la Guía legislativa de UNCITRAL acerca del régimen de la insolvencia $(2004)^{4}$, la que concibe la «reorganización» como el «proceso mediante el cual se restablece la prosperidad financiera y la viabilidad del negocio de un deudor si se mantiene el negocio en marcha por diversos medios, como, por ejemplo, la condonación de la deuda, la reestructuración de la deuda, la capitalización de esta y la venta de la empresa (o de partes de ella) como negocio en marcha» [núm. 11, literal kk)]. Dicho de otra manera, las propuestas que dan origen al acuerdo de reorganización de acuerdo con la LRALAEP tienen un objeto que no es especialmente indicativo de un contenido jurídico (acaso asimilable a la renuncia de la acción de liquidación) ${ }^{5}$, sino que comporta una formulación económica amplia (dar una nueva estructura al activo y pasivo) destinada a promover el rescate de la empresa en crisis garantizando su conservación $^{6}$. Su finalidad es, entonces, promover el reemprendimiento de la empresa deudora y no su desaparición (artículo 93 LRLAEP). De ahí que, en el marco de la Ley 20.416, la reorganización sea la alternativa opuesta al cierre de la pequeña y mediana empresa, ya que ella está pensada como un procedimiento enderezado a que la empresa deudora supere su estado de insolvencia (artículo 22 IV del artículo undécimo de dicha ley), el que existe si ella está en imposibilidad de pagar una o más de sus obligaciones (artículo $2^{\circ}$ del artículo undécimo de dicha ley). De lo contrario, por ejemplo, carecería de sentido la posibilidad que tienen los acreedores garantizados con prenda o hipoteca para solicitar que determinados bienes de la empresa deudora pueda ser declarados por

${ }^{3}$ Si bien en la tramitación legislativa de la Ley 20.720 no se dejó constancia expresa de las fuentes consultadas para la preparación del proyecto (artículo 19 II CC), la influencia del ordenamiento colombiano es evidente en muchos aspectos. Entre ellos cabe destacar, por ejemplo, la incorporación de la ley modelo de insolvencia transfronteriza, el tratamiento de la continuidad de los contratos, o la denominación de los distintos procedimientos.

${ }^{4}$ Rodríguez Espitia, J. J., Nuevo régimen de insolvencia, Universidad del Externado de Colombia, Bogotá, 2007, p. 35.

${ }^{5}$ Puga, J. E., Derecho concursal. El acuerdo de reorganización, Editorial Jurídica de Chile, Santiago, $4^{\mathrm{a}}$ ed., 2014, p. 357.

${ }^{6}$ En el contexto de la legislación hoy derogada, PUGA, J. E., Derecho concursal. El convenio de acreedores, Editorial Jurídica de Chile, Santiago, $3^{\mathrm{a}}$ ed., 2006, p. 177, había insistido en la libertad contractual como principio que gobernaba el objeto de los convenios, de suerte de ser admisibles múltiples formas para sanear la insolvencia del deudor. En similar sentido se había pronunciado antes Puelma, Á., Curso de derecho de quiebras, Editorial Jurídica de Chile, Santiago, $3^{a}$ ed., 1983, p. 212. Esto significa que el sistema jurídico ofrece una liberalización del contenido de estas respuestas concursales favoreciendo las soluciones negociales. La idea había sido asumida por la Ley 18.175, cuyo texto original preveía varios ejemplos no taxativos relacionados con este punto (artículo 173), pero que fue posteriormente modificada por la Ley 20.073, para simplemente señalar que "[1]as proposiciones de convenio judicial preventivo pueden versar sobre cualquier objeto lícito para evitar la declaración de quiebra, salvo sobre la alteración de la cuantía de los créditos fijada para determinar el pasivo" (artículo 178 del Libro IV del Código de Comercio). Véase Goldenberg, J. L., "Los acuerdos de reorganización de la empresa deudora en el derecho concursal chileno”, en GARCíA-CRUCES, J. A., (dir.), Las soluciones negociadas como respuesta a la insolvencia empresarial. Reformas en el derecho comparado y crisis empresarial, ThomsomReuters/Aranzadi, Madrid, 2014, pp. 75-81. 
el tribunal como no esenciales para la continuidad de su giro (artículo 94 LRLAEP), lo que tiene incidencia en la forma de ejercicio de sus derechos respecto de un acuerdo ya aprobado (artículo 95 LRLAEP).

Eso significa que la razón por la que el $30^{\circ}$ Juzgado Civil de Santiago rechazó la solicitud de reorganización era errada: en realidad, el problema no era que no estuviese acreditado un discutible presupuesto material para dar curso a un procedimiento concursal, como después sostuvo la Corte, sino que en paralelo existía (con la consiguiente litispendencia) un juicio destinado a disolver la cooperativa, el que impedía, de prosperar, la reorganización ${ }^{7}$. Si se disolvía de esta manera la cooperativa, lo que correspondía era que la comisión liquidadora pidiese posteriormente su liquidación en sede concursal. Dicho de otra forma, el obstáculo para la reorganización existía igualmente con independencia de si la insolvencia era o el presupuesto material para dar curso al procedimiento concursal. La razón del rechazo de la solicitud de reorganización provenía del hecho de que ante otro tribunal se estaba discutiendo al tiempo la disolución forzada de la cooperativa, la que trae consigo el inicio de la fase de liquidación societaria (artículo 47 LGC).

Después de estas consideraciones, la pregunta que todavía es posible hacerse es si son admisibles en el derecho chileno las reorganizaciones liquidatorias, vale decir, aquellos acuerdos de reorganización cuya finalidad última es proceder a la completa realización de los activos de la empresa deudora para proceder al pago de su pasivo ${ }^{8}$. Resulta indudable que esta figura, que busca eludir la disciplina propia de la liquidación concursal, no es admisible dentro del sentido de revitalización comercial de la reorganización, pues supone la sustitución de una economía real y de tejido productivo por una de pura especulación. Desde el punto de vista dogmático, el tema rebasa los estrechos límites de este comentario, pero el punto ya ha sido objeto de alguna (todavía provisional) jurisprudencia en el marco de impugnaciones a acuerdos de reorganización

${ }^{7}$ La cuestión estriba en que el procedimiento de reorganización no contempla una oportunidad de oposición a la solicitud ni de impugnación de la resolución que la declara. Con todo, ya que se trata de una gestión no contenciosa (artículo 817 CPC), es teóricamente posible concebir la intervención de un tercero en calidad de legítimo contradictor (artículo 823 CPC).

${ }^{8}$ Contador, N./Palacios, C., Procedimientos concursales, ThomsomReuters, Santiago, 2015, p. 80. Puga, Derecho concursal. El acuerdo de reorganización, cit., p. 205, por su parte, sostiene que es posible argumentar favorablemente acerca de los acuerdos liquidatorios a partir de un paralelo con la admisión de una ejecución en el marco del procedimiento concursal de renegociación de la persona deudora. Sin embargo, tal conclusión no parece convincente. Si se observa dicha normativa, la audiencia de ejecución regulada en el artículo 267 LRLAEP tiene lugar precisamente por el rechazo de la propuesta en la audiencia de renegociación (y así se indica también en el artículo 266 VIII LRLAEP). Adicionalmente, el artículo 266 XI LRLAEP dispone que el acuerdo de renegociación puede versar sobre cualquier objeto que propenda a repactar, novar o remitir las obligaciones de la persona deudora (idea que el artículo 93 LRLAEP expresa a propósito de la reorganización), lo que evidentemente no incluye fórmulas ejecutivas. Por el contrario, el artículo 267 LRLAEP establece que el objetivo de la audiencia de ejecución es la deliberación y votación de una propuesta de realización del activo del deudor presentada por la Superintendencia de Insolvencia y Reemprendimiento, conteniendo la forma en que serán realizados los bienes de la persona deudora y el pago de los acreedores señalados en dicho acuerdo, todo ello conforme a las reglas de prelación de créditos. 
de esta clase merced al artículo 85 núm. 6 LRLAEP9 . Esa jurisprudencia se ha pronunciado en contra de esta práctica forense que desnaturaliza un procedimiento concursal diseñado para permitir el funcionamiento de la empresa bajo una nueva estructura de su activo y pasivo que la haga económicamente viable como agente del mercado. Como ya insinúa su tenor literal, reorganizar significa dar una ordenación al activo y pasivo de la empresa deudora que sea distinta (por ejemplo, en lo que atañe al pasivo, remitiendo, novando o repactando los créditos) y que resulte más eficaz para la continuidad de su giro (conservándose para ello los bienes que sean esenciales para ese fin), sin hacerla desaparecer del mercado.

\footnotetext{
${ }^{9}$ Véase las sentencias de 23 de octubre de 2017 dictada por el $21^{\circ}$ Juzgado Civil de Santiago (procedimiento concursal de reorganización de Delta Ingeniería y Construcción S.A., rol núm. 28.289-2016) y de 14 de diciembre de 2017 dictada por $17^{\circ}$ Juzgado Civil de Santiago (procedimiento concursal de reorganización de la Sociedad Áridos y Pétreos Maipo S.A., rol núm. 806-2017). La primera de ellas fue confirmada por la Corte de Apelaciones de Santiago mediante sentencia de 3 de mayo de 2018 (rol núm. 13.730-2017). A esta fecha (4 de julio de 2018) se encuentran pendientes los recursos de casación contra este último fallo y de apelación contra la segunda de las sentencias antes referida.
} 
